\title{
FUTURE PRIMARY TEACHERS' KNOWLEDGE AND UNDERSTANDING OF ENVIRONMENTAL QUALITY ISSUES - A QUESTIONNAIRE SURVEY
}

\author{
PAPANASTASIOU D.K. ${ }^{1, *}$ \\ AVGOLOUPIS S. ${ }^{1}$ \\ MELAS D. ${ }^{2}$ \\ IKONOMIDIS S. ${ }^{1}$
}

\author{
${ }^{1}$ Section of Sciences and New Technologies, \\ School of Primary Education, Faculty of Education, \\ Aristotle University of Thessaloniki, GR-54124 Thessaloniki, Greece \\ ${ }^{2}$ Laboratory of Atmospheric Physics, School of Physics, \\ Aristotle University of Thessaloniki, \\ Campus Box 149, GR-54124 Thessaloniki, Greece
}

Received: $26 / 11 / 2012$

Accepted: 01/10/2014

Available online: 03/10/2014 *to whom all correspondence should be addressed: e-mail: dkpapan@auth.gr

\section{ABSTRACT}

This paper aims to investigate students' awareness regarding the factors that affect the environmental quality in university classrooms. For this purpose a questionnaire survey was conducted, in which 314 undergraduate students of the School of Primary Education, Aristotle University of Thessaloniki, participated. The questionnaire was developed for this survey and includes questions related to indoor thermal comfort (ITC) conditions and indoor air quality (IAQ). The analysis revealed that the vast majority of the students were aware that temperature and humidity are the two factors that mainly determine the ITC levels. In general, they are also aware that the ITC levels are affected by classroom's and individual's characteristics. The most accepted factors considered by the students to affect the IAQ were smoking $(95 \%)$ and dust $(90 \%)$, while the less accepted factors were furniture $(17 \%)$, wallpapers (21\%) and use of printer, photocopier (29\%). The results underline the need to improve students' knowledge about the factors that affect IEQ and that measures can be taken to improve it.

Keywords: Indoor thermal comfort, indoor air quality, questionnaire, student awareness

\section{Introduction}

Environmental quality in non-industrial buildings has been the subject of many studies conducted worldwide due to its adverse health effects that include discomfort, respiratory problems, allergies etc (Jones, 1999; Mendell and Mirer, 2009; Sundell, 2004; Wu et al., 2007). 60\% of the asthmatic disorders in Greece could be attributed to the indoor environmental pollution (Greek Parliament, 2010). The effects can be more serious for vulnerable groups like children, the elderly and those people already suffering from respiratory or allergic diseases. IEQ can be assessed by studying ITC levels and IAQ.

Many studies about IEQ and its effects for various types of non-industrial buildings have been published, like for residential buildings (Lee et al., 2002; Santamouris et al., 2007), offices and other working areas (Helmis et al., 2009; Lahtinen et al., 2004), schools and universities (Daisey et al., 2003; Valavanidis and Vatista, 2006), hospitals (Dascalaki et al., 2008) and museums (Schieweck and Salthammer, 2011). Many parameters influence the ITC conditions, including environmental parameters (air's temperature, humidity and velocity, thermal radiation of indoor surfaces) and parameters related to the metabolic rate and the skin temperature of the occupants (gender, age, clothing, activity) (Höppe, 1988; Höppe and Martinac, 1998). Many air pollutants can be detected indoors, including asbestos, radon, combustion products, formaldehyde, volatile organic compounds, biological pollutants etc (Harada et 
al., 2010). Many factors have been implicated for the degradation of $I A Q$, including smoking, use of air conditioners and heating devices, office equipment, human activities, outdoor atmospheric pollution, etc. (Franchi et al., 2006).

In order to improve IEQ, various measures can be taken, that require integrated and multidisciplinary approaches. Emissions by known sources could be decreased; guidelines for buildings' design and ventilation could be set; information campaigns on indoor air pollution (IAP) sources and on the use of environmental friendly products and possible substitutes of harmful ones could be organized. The latter is very important as many people may not be aware of the factors that influence IAQ. Personal initiatives are very important and the problem definitely needs to receive the proper political attention. Additionally, topics related to IEQ could be introduced to the environmental education courses that are offered to school and university students.

This study uses a questionnaire aiming to identify conceptions and misconceptions about the factors that affect IEQ among Greek undergraduate students. The use of a questionnaire is a widely applied research technique, which has been utilized many times to assess IEQ (Aarnio et al., 2005; Bluyssen, 2000; Cho et al., 2011).

\section{Materials and methods}

This study used part of the results of a questionnaire survey that was conducted in January 2012 among the undergraduate students of the School of Primary Education of the Aristotle University of Thessaloniki. This population was selected for the research as the graduates of the School of Primary Education are candidate environmental educators for primary students. The students were informed that the questionnaire served research purposes and were asked to answer it individually and anonymously before the beginning of a course. The questionnaire was distributed to all the students who attended the $3^{\text {rd }}$ or higher semester of studies and was filled voluntarily. The questionnaire that was distributed to the students was developed for this study. It was inspired by an Örebro questionnaire (i.e. the "MM 040 School"). MM questionnaires were developed at the Department of Occupational and Environmental Medicine in Örebro, Sweden. The version "MM 040 School" is based on the basic questionnaire "MM 040 NA" and includes more detailed questions about the physical environment. The basic version "MM 040 NA" includes questions about the perceived indoor climate and air quality, medical symptoms and their presumed relation to the indoor environment, psychosocial environment and background factors (Andersson, 1998). The questionnaire consists of four parts. The $1^{\text {st }}$ part includes background questions about gender, birth year, semester of studies and smoking habits. The $2^{\text {nd }}$ part includes questions related to the factors that affect ITC and IAQ, while the $3^{\text {rd }}$ part aims to investigate the environmental conditions found in the university classrooms. The $4^{\text {th }}$ part asks for a classification of the university classrooms according to indoor environmental conditions. In order to check the reliability of the developed questionnaire a pilot test was conducted. This test aimed to determine the time required to fill the questionnaire, whether the meaning and the wording of the questions were comprehensible by the students and whether some of the questions were difficult to be answered briefly. This method has also been followed by other studies (Baumann and Kolotylo, 2009; Glanz and Steffen, 2008). The questionnaire was initially distributed to a small group of students (i.e. 17) who attended the $3^{\text {rd }}$ or higher semester of studies. As soon as the students filled the questionnaire, they were asked to make proposals orally on how the questionnaire could be improved and to mark any confusing statements. The students asked for a few clarifications about the wording of some questions. Their comments were taken into account and the final version of the questionnaire was developed. The present study used the answers given to the background questions (in order to identify the sample's characteristics) and to the questions of the $2^{\text {nd }}$ part (questions a to f). Below follows the description of these questions.

Question a aimed to investigate if the students were aware of the two physical parameters (i.e. air's temperature and humidity) that mainly affect the ITC conditions. Question $b$ aimed to examine students' deeper knowledge on the factors that affect ITC conditions. All of the factors examined in 
questions $\mathrm{c}$ and e affect the IAQ directly or indirectly. So, these questions aimed to examine basic misconceptions. However, question e also aimed to examine students' deeper knowledge about some factors. This was the reason to exclude these factors from question $c$ and include them in a separate question (question e). As some of the factors can affect IAQ both positively and negatively, it was pointed out to the students that if they think that a factor can have both a positive and a negative impact, they have to tick both answers (i.e. yes, positively; yes, negatively) in question e. Seven factors of those introduced in question $\mathrm{c}$ were included in question $\mathrm{d}$. The selection of these factors was based on the criterion that their influence on IAQ is not obvious, like it is, for example, for cleaning, smoking, etc. Question $f$ is similar to question $d$. The selection of the examined factors, from those introduced in question e, was based on the criterion that their influence on IAQ may be positive, negative or both. So, questions $d$ and $f$ aimed to investigate students' deeper knowledge on how every factor affects IAQ.

\section{Results and discussion}

\subsection{Sample characteristics}

314 questionnaires were collected and analyzed. 281 were filled by females, while 29 were filled by males. This sex analogy is typical for the Schools of Primary Education in Greece, as these schools are mainly preferred by females. 4 students didn't give their gender. Information about the birth year and the semester of studies of the 314 undergraduate students is provided in tables 1 and 2, respectively.

Table 1. Birth year of the undergraduate students that took part in the survey

\begin{tabular}{ccccccccccccccccc}
\hline \multicolumn{11}{c}{} \\
& 73 & 77 & 79 & 80 & 81 & 82 & 84 & 85 & 86 & 87 & 88 & 89 & 90 & 91 & $92 \begin{array}{c}\text { Not } \\
\text { given }\end{array}$ \\
\hline No & 1 & 1 & 1 & 2 & 1 & 2 & 1 & 1 & 1 & 1 & 1 & 7 & 105 & 82 & 101 & 6 \\
\hline
\end{tabular}

Table 2. Semester of studies of the undergraduate students that took part in the survey

\begin{tabular}{ccccccccc}
\hline \multicolumn{10}{c}{ Semester of studies } \\
\hline No & 3 & 5 & 6 & 7 & 8 & 9 & 11 & Not given \\
\hline & 108 & 58 & 1 & 138 & 2 & 4 & 1 & 2 \\
\hline
\end{tabular}

\subsection{Question a}

Question's statement was: "Which of the following physical air properties affect the ITC levels?". The examined properties $(\mathrm{P})$, the available answers and the percentages of the given answers are presented in table 3. Few students didn't provide an answer for P2 and P3 (6 and 8, respectively), while more students didn't provide an answer for P1 and P4 (22 and 26, respectively). The answers confirm that the vast majority of the students are aware that air's temperature (94\%) and humidity (88\%) are the two factors that mainly determine the ITC levels. However, some students either don't know (almost half of them) or they are confused (almost one fourth of them) regarding the impact of air's pressure and density to ITC conditions. Their unawareness or confusion could be attributed to lack of knowledge about the relations between physical parameters. Consequently, this topic could be included in the undergraduate curriculum of the School of Primary Education.

Table 3. Percentage (\%) of every available answer given to question a

\begin{tabular}{ccccc}
\hline \multirow{2}{*}{ Available answer } & \multicolumn{5}{c}{ Property } \\
\cline { 2 - 5 } & Pressure (P1) & Temperature (P2) & Humidity (P3) & Density (P4) \\
\hline Yes & 29 & 94 & 88 & 21 \\
\hline No & 24 & 2 & 6 & 26 \\
\hline I don't know & 47 & 4 & 6 & 53 \\
\hline
\end{tabular}




\subsection{Question b}

Question's statement was: "Which of the following factors referring to classroom and to individual's conditions affect the ITC levels?". 9 factors (F) were examined. The available answers and the percentages of the given answers are presented in table 4. Few students didn't provide an answer for some factors, their number ranging between 2 and 12, depending on the factor. The most accepted factors considered by the students to affect the ITC levels are ventilation (F1-94\%), construction materials (F2-91\%), clothing (F8-88\%), proper use of heating, cooling and ventilation systems (F4-87\%) and type of activity (F9-82\%). The students were aware that ITC levels are influenced by classroom's characteristics (F1 to F5), as well as by individual's condition (F6 to F9), as the most accepted factors are included in both factor groups. The less accepted factor was gender (F6-22\%), a fact that shows that the majority of the students was not aware that differences in thermal comfort between males and females can be detected (Karjalainen, 2007). 36\% of the students haven't noticed that electric appliances (F5) release heat when they operate, while $52 \%$ of them don't know that objects can absorb heat (F3). $58 \%$ of the sample knows that the elderly have more demanding requirements than other age groups regarding the indoor climate conditions (F7) (Hwang and Chen, 2010).

Table 4. Percentage (\%) of every available answer given to question $b$

\begin{tabular}{|c|c|c|c|c|c|c|c|c|c|}
\hline \multirow[b]{2}{*}{ Available answer } & \multicolumn{9}{|c|}{ Factor (F) } \\
\hline & 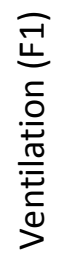 & 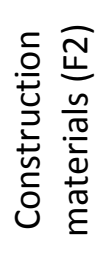 & 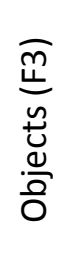 & 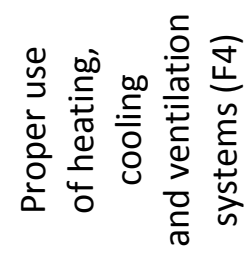 & 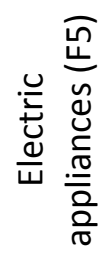 & 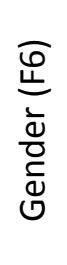 & 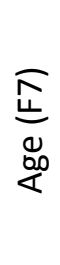 & 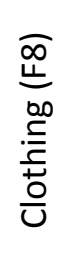 & 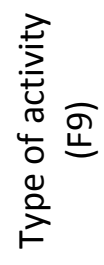 \\
\hline Yes & 94 & 91 & 48 & 87 & 64 & 22 & 58 & 88 & 82 \\
\hline No & 3 & 5 & 22 & 4 & 16 & 64 & 32 & 7 & 7 \\
\hline I don't know & 3 & 4 & 30 & 9 & 20 & 14 & 10 & 5 & 11 \\
\hline
\end{tabular}

\subsection{Question c}

Question's statement was: "Do you think that the following factors affect IAQ?". 17 factors (F) were examined. The available answers and the percentages of the given answers are presented in table 5. Few students didn't provide an answer for some factors, their number ranging between 2 and 10, depending on the factor. The most accepted factors considered by the students to affect IAQ were smoking (F16-95\%), dust (F8-90\%), ventilation (F4-84\%), use of cosmetics (F6-81\%), use of cleaning materials, detergents, materials for moth protection, etc (F5-80\%) and micro-organisms (F10-80\%), while the less accepted factors were furniture (F11-17\%), use of printer, photocopier (F13-29\%), lighting (F1-37\%) and electromagnetic radiation, electric and magnetic fields (F2-38\%). A considerable number of students (75\%) accept that paints, varnishes, polishes, etc (F12) influence IAP levels. However, it seems that $25 \%$ of the sample is not informed about the paints that don't include volatile organic compounds that are available at the stores or that it hasn't realized that the odors produced for example by polishes worsen IAQ. $72 \%$ of the students accept that the air that enters a house can transport indoors air pollutants from the outdoor environment (F7). However, $28 \%$ of them is not aware that this often occurs in the city centre. Nevertheless, the idea that ventilation (F4) refreshes indoor air and dilutes or removes indoor air pollutants is well accepted by the students (84\%). More than half of the students (64\%) believe that construction materials (F15) and pets (F17) contribute to IAP. However, $36 \%$ of them are not informed that construction materials may contain some elements that are dangerous for health and that pets' fur and the insects that may live in it may trigger respiratory disorders. Almost half of the students implicated acariens (F9) and operation of electric appliances (F14) for IAQ's deterioration ( $52 \%$ and $48 \%$, respectively). However, the other half is not aware of the adverse health effects that acariens could induce. It is worth mentioning that cleaning (F3) was ranked $7^{\text {th }}(79 \%)$, although its effect on air quality seems obvious. Additionally, $20 \%$ of the students are not informed that 
19\% of Greek households have humidity problems (F10) (Healy and Clinch, 2002). An interesting finding is that the less accepted factor was furniture (F11). Only $17 \%$ of the students think that furniture can contribute to IAQ's degradation, while $68 \%$ of them think that it can't and the rest $15 \%$ does not know. Consequently, a great number of students are not aware that formaldehyde can be released by furniture made by artificial wood, which are widely promoted by the market, being inexpensive and fancy. Additionally, the $2^{\text {nd }}$ less accepted factor is the use of printer and photocopier (F13), as more than two thirds of the students don't know that particles and gases can be released into air during the operation of these office appliances.

Table 5. Percentage (\%) of every available answer given to question c

\begin{tabular}{|c|c|c|c|c|c|c|c|c|c|c|c|c|c|c|c|c|c|}
\hline \multirow[b]{2}{*}{$\begin{array}{c}\text { Available } \\
\text { answer }\end{array}$} & \multicolumn{17}{|c|}{ Factor (F) } \\
\hline & 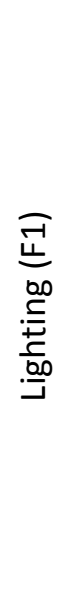 & 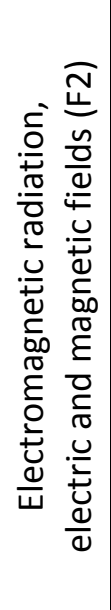 & 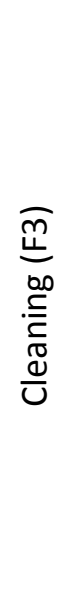 & 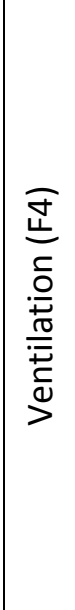 & 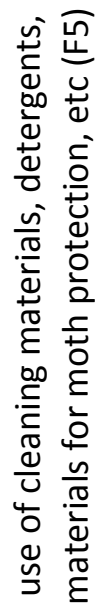 & 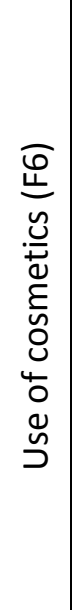 & 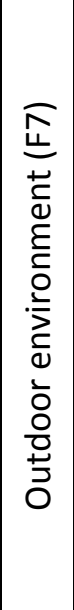 & 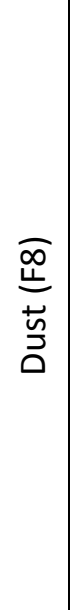 & 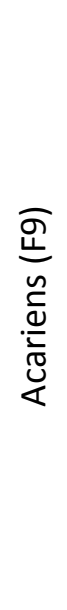 & 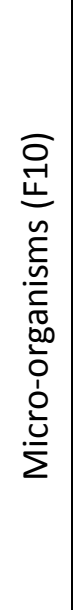 & 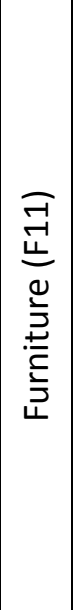 & 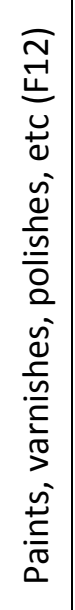 & 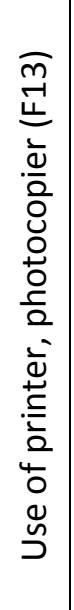 & 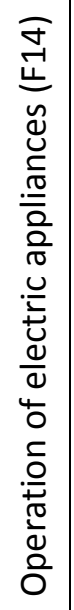 & 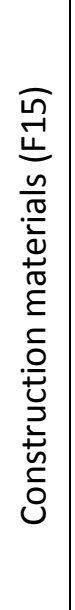 & 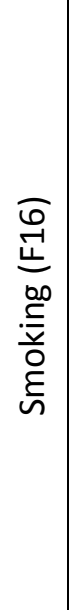 & 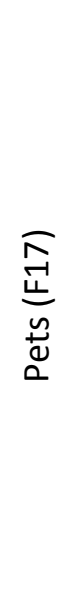 \\
\hline Yes & 37 & 38 & 79 & 84 & 80 & 81 & 72 & 90 & 52 & 80 & 17 & 75 & 29 & 48 & 64 & 95 & 64 \\
\hline No & 40 & 22 & 14 & 5 & 8 & 14 & 14 & 4 & 20 & 8 & 68 & 15 & 43 & 28 & 18 & 2 & 20 \\
\hline I don't know & 23 & 40 & 7 & 11 & 12 & 5 & 14 & 6 & 28 & 12 & 15 & 10 & 28 & 24 & 18 & 3 & 16 \\
\hline
\end{tabular}

\subsection{Question d}

The statement of question $\mathrm{d}$, which was an open type question, was: "If you previously answered that "factor name" affects IAQ, how is this achieved?". Factors F1, F2, F4, F11, F13, F14 and F15 of those included in question c were examined and the percentages of the students who provided an explanation of how it does it were $61 \%, 43 \%, 56 \%, 58 \%, 56 \%, 54 \%$ and $60 \%$, respectively. The following percentages refer to the number of students that gave an explanation for each factor. The majority (77\%) think that lighting affects $I A Q$, due to heat released by lamps. It seems that these students believe that air quality worsens when air is warm, bringing out a misconception. However, it should be noticed that high temperatures support the production of toxic gases (e.g. formaldehyde) and secondary aerosols, but most probably the students are not aware of it, as none of them wrote something relevant. Additionally, the higher the air temperature is, the dryer the air becomes, but nobody mentioned this heat effect either. $18 \%$ of the students wrote that electromagnetic radiation, electric and magnetic fields influence $I A Q$, because they increase air temperature, while another $18 \%$ stated that various types of radiation are emitted. A $14 \%$ provided an explanation related to the fact that electric and magnetic fields can modify the electric properties of the particles, influencing the ions balance in the air and the dust deposition processes. $74 \%$ of the students answered that ventilation improves air quality in underground and semi-underground indoor spaces. However, no one mentioned that when underground spaces are properly ventilated, radon's concentration is reduced, resulting to the alleviation of a major problem in these spaces. The answers given regarding the impact of furniture on IAQ were various. $19 \%$ and $26 \%$ of the students believes that furniture degrades air quality when they are old or dusty, respectively. $13 \%$ and $10 \%$ thinks that furniture affects IAQ as they absorb heat and occupy some space, respectively. Only $16 \%$ supported the most important idea about furniture's 
contribution (i.e. release of odors and other gases). It is known that toxic substances contained in paints, varnishes, polishes, etc used for furniture's decoration and maintenance could be released to the air. Additionally, the impact of formaldehyde released by artificial wood furniture on IAQ is well documented. $16 \%$ and $41 \%$ of the students believe that the radiation and the heat, respectively, released by printers and photocopiers contribute to IAQ's degradation. However, only $24 \%$ noticed that gases and particles are released to the air when these devices operate. More students (66\%) believe that the impact of the operation of electric appliances is also due to the released heat and fewer students $(15 \%)$ that it is due to the released odors, particles and smoke. This fact supports the misconception stated above about the misinterpreted relation between heat and air quality. Although $28 \%$ of the students related the impact of construction materials to IAQ with the level of thermal insulation, more than half of them (54\%) supported that construction materials can release odors, particles, toxic gases and metals to the air, triggering an increase of IAP levels. It is worth mentioning that many students underlined the adverse health effects of asbestos and that one student wrote that some construction materials (e.g. granite) emit ionizing radiation.

\subsection{Question e}

Question e had the same statement as question c. 11 factors (F) were examined. The available answers and the percentages of the given answers are presented in table 6.

Table 6. Percentage (\%) of every available answer given to question e

\begin{tabular}{|c|c|c|c|c|c|c|c|c|c|c|c|}
\hline \multirow[b]{2}{*}{$\begin{array}{l}\text { Available } \\
\text { answer }\end{array}$} & \multicolumn{11}{|c|}{ Factor (F) } \\
\hline & 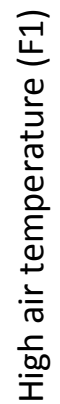 & 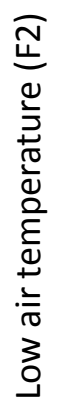 & 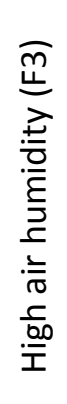 & 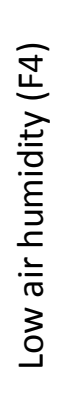 & 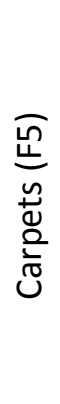 & 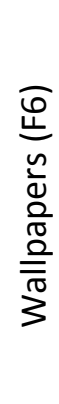 & 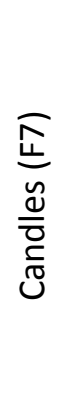 & 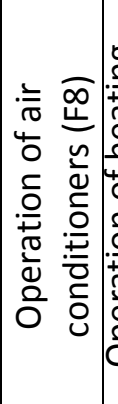 & 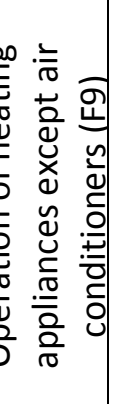 & 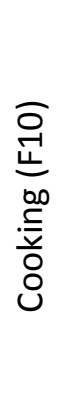 & 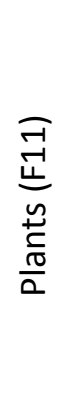 \\
\hline Yes, positively & 7 & 15 & 3 & 37 & 9 & 4 & 12 & 14 & 17 & 3 & 31 \\
\hline Yes, negatively & 41 & 25 & 73 & 24 & 36 & 15 & 35 & 52 & 39 & 60 & 27 \\
\hline $\begin{array}{l}\text { Yes, positively } \\
\text { and negatively }\end{array}$ & 22 & 20 & 7 & 8 & 8 & 2 & 8 & 18 & 16 & 4 & 24 \\
\hline Sum of "yes" answers & 70 & 60 & 83 & 69 & 53 & 21 & 55 & 84 & 72 & 67 & 82 \\
\hline No & 11 & 14 & 3 & 10 & 28 & 45 & 19 & 4 & 6 & 12 & 5 \\
\hline I don't know & 19 & 26 & 14 & 21 & 19 & 34 & 26 & 12 & 22 & 21 & 13 \\
\hline
\end{tabular}

Few students didn't provide an answer for some factors, their number ranging between 3 and 16, depending on the factor. The most accepted factors considered by the students to affect IAQ positively, negatively or both were operation of air conditioners (F8-84\%), high air humidity (F3-83\%) and plants (F11-82\%), while the less accepted factor was the wallpapers (F6-21\%). The acceptance of the other factors ranged between $53 \%$ and $72 \%$. Regarding the operation of the air conditioners (F8), it seems that $30 \%$ of the students are not aware that micro-organisms can grow on the filters and pipes and can be released indoors, if the system is not regularly cleaned and well maintained. Additionally, $22 \%$ of the students are not aware that particles and odors are released when heating appliances except air conditioners, like fireplaces and gas stoves, (F9) operate. It is worth mentioning that only $24 \%$ of the sample knows that plants ( $\mathrm{F} 11$ ) can affect positively (by absorbing $\mathrm{CO}_{2}$ ) or negatively (by absorbing $\mathrm{O}_{2}$ ) the IAQ. This percentage is slightly higher than the percentage of students who don't believe or don't know that plants affect air quality (18\%). Not accepting wallpapers (F6) as a cause of IAQ's deterioration is also a misconception; however, students are not expected to know much about wallpapers, as their 
use is very limited in Greece. Concerning high air humidity (F3) and high (F1) and low (F2) air temperature, the conclusions are similar to those drawn by question $\mathrm{c}$ and $\mathrm{d}$, respectively. It is rather confusing that half of the students (37\%) who answered that high air humidity (F3) affects air quality negatively (73\%) believe that low air humidity (F4) affects air quality positively. Carpets (F5) can negatively influence IAQ in many ways, but less than half of the students are aware of one of them. Acariens can live in carpets, while dust deposition and re-suspension is favored. Additionally, toxic substances (e.g. caprolactam) can be released to the air by the materials used to produce carpets. These impacts are more pronounced in the case of wall to wall carpeting. Some $35 \%$ of the students agreed with the correct statement that candles (F7) affect IAQ negatively, while 33\% of them don't think or don't know that particles can be released in the air during cooking (F10).

\subsection{Question $f$}

Question $\mathrm{f}$ consisted of 2 open type sub-questions. The statement of the $1^{\text {st }}$ sub-question was: "If you previously answered that "factor name" affects IAQ positively, how is this achieved?". Factors 2, 6, 8, 9, 10,11 and 12 of those included in question e were examined and the percentages of the students who provided an explanation of how it does it were $47 \%, 43 \%, 49 \%, 57 \%, 42 \%, 15 \%$ and $62 \%$, respectively. The following percentages refer to the number of students who gave an explanation for each factor. Although low temperatures are associated with high humidity levels, $35 \%$ of the students believe that low air temperature is related to better air quality, claiming that low temperatures don't favor the growth of microbes and micro-organisms. Additionally, 23\% related low temperatures with clean and not stuffy air. The majority of the students (74\%) have confused the benefit from carpets' use with their impact on air quality; they wrote that carpets improve air quality, as they provide warmth and thermal insulation. Significant misconceptions are extracted regarding candles' effect on IAQ. $20 \%$ of the students think that candles absorb odors, $20 \%$ think that air quality is improved as candles release scents, $23 \%$ stated that candles release heat and therefore air quality is improved, while $13 \%$ believe that the relaxing conditions that are usually produced by candles at home are related to better air quality. The majority of the students who think that the operation of air conditioners and heating devices contribute to better air quality (59\% and $79 \%$, respectively) answered that comfortable temperature conditions are attained through the use of air conditioners and heating devices. This idea is not wrong, considering the relation of high and low temperature with air quality, but probably, their answers just support the misconception mentioned above regarding the relation between heat and air pollution. The idea that a room is ventilated when an air conditioner operates is supported by the $25 \%$ of the students. Almost all of the students $(90 \%)$ who answered that plants affect IAQ positively had in mind that plants absorb $\mathrm{CO}_{2}$ and release $\mathrm{O}_{2}$.

The statement of the $2^{\text {nd }}$ sub-question was: "If you previously answered that "factor name" affects IAQ negatively, how is this achieved?". Factors 2, 5, 6, 8, 9, 10, 11 and 12 of those included in question e were examined and the percentages of the students who provided an explanation of how it does it were $37 \%, 30 \%, 65 \%, 57 \%, 57 \%, 50 \%, 58 \%$ and $63 \%$, respectively. The following percentages refer to the number of students who gave an explanation for each factor. $69 \%$ stated that air quality is worsened when air becomes colder. 33\% think that ventilation affects air quality negatively, as pollutants can be transported indoors from the outdoor environment. Almost all of the students (92\%) are aware of how carpets influence IAQ negatively. $77 \%$ of the students know that $\mathrm{O}_{2}$ is consumed and that $\mathrm{CO}_{2}$, smoke, odors and other toxic gases are released to air when candles are burning. Similar factors, as well as emission of particles, are thought to account for the negative effects caused by the operation of heating devices. The operation of air conditioners degrades IAQ, as air becomes dryer (20\%), no fresh air enters the room (15\%), or when the filters are not cleaned (40\%). The latter was related to the release of micro-organisms and substances that can cause health problems (i.e. allergies). $85 \%$ of the students stated that odors, particles and vapors released when cooking contribute to IAQ's degradation, while $87 \%$ stated that plants affect IAQ negatively, absorbing $\mathrm{O}_{2}$ and releasing $\mathrm{CO}_{2}$. Pollen and microorganisms that live on plants can also have negative impact, but they were not mentioned by the students. 


\section{Conclusions}

314 prospective Greek teachers participated in a questionnaire survey that aimed to assess their knowledge on the factors that influence IEQ. The findings of this study are highlighted below.

1. $94 \%$ and $88 \%$ of the students are aware that air's temperature and humidity, respectively, are the two factors that mainly determine the ITC levels.

2. Students were asked to decide whether 9 given factors affect ITC levels or not. It is scientifically accepted that all of them affect ITC levels. Their ranking from the more accepted to the less accepted factor is: ventilation (94\%), construction materials (91\%), clothing (88\%), proper use of heating, cooling and ventilation systems (87\%), type of activity (82\%), operation of electric appliances $(64 \%)$, age $(58 \%)$, heat absorption by objects $(48 \%)$ and gender $(22 \%)$.

3. Students were asked to decide whether 28 given factors affect IAQ or not. It is scientifically accepted that all of them affect IAQ directly or indirectly. Their ranking from the more accepted to the less accepted factor is: smoking (95\%), dust (90\%), operation of air conditioners $(84 \%)$, ventilation $(84 \%)$, high air humidity $(83 \%)$, plants $(82 \%)$, use of cosmetics $(81 \%)$, microorganisms $(80 \%)$, use of cleaning materials, detergents, materials for moth protection, etc (80\%), cleaning $(79 \%)$, paints, varnishes, polishes, etc $(75 \%)$, operation of heating devices $(72 \%)$, outdoor atmospheric pollution (72\%), high air temperature (70\%), low air humidity levels (69\%), cooking $(67 \%)$, construction materials $(64 \%)$, pets $(64 \%)$, low air temperature $(60 \%)$, candles $(55 \%)$, carpets, wall to wall carpeting $(53 \%)$, acariens $(52 \%)$, operation of electric appliances (48\%), electromagnetic radiation, electric and magnetic fields (38\%), lighting (37\%), use of printer, photocopier $(29 \%)$, wallpapers $(21 \%)$, furniture $(17 \%)$

4. Some misconceptions were detected. The most important refer (a) to the relation between heat/high temperature and air pollution, (b) to the impact of carpets, acariens, furniture, wallpapers and candles to IAQ and (c) to the positive and negative effect of plants on IAQ.

5. The survey's results support the idea that many students are not aware of the factors that affect IAQ. This is a serious point not only because they will teach environmental education to primary students in the future, but also for their everyday life. Better knowledge in this field will help them improve environmental conditions at their home and take the proper decisions when renovating, decorating, etc.

6. Topics related to IEQ could be discussed in the framework of school and university courses related to natural sciences, environment and buildings.

\section{Acknowledgments}

The work of Dr. D.K. Papanastasiou has been funded by the Research Committee of the Aristotle University of Thessaloniki, under the scholarship programme "Scholarships for excellent postdoctoral researchers for 2011" (contracts: 50141/292859, 50141/292861). Additionally, the authors would like to thank the Dean of the Faculty of Education and the President and the Faculty of the School of Primary Education for their help during the survey, as well as the School's students for answering the questionnaire.

\section{References}

Aarnio P., Mussalo-Rauhamaa H., Mäkinen-Kiljunen S., Saarela K. and Loft S. (2005), Indoor air problems in a healthcare centre - a case report of a follow-up, Indoor Built Environ., 14, 433-441.

Andersson K. (1998), Epidemiological approach to indoor air problems, Indoor Air, 4 suppl., 32-39.

Baumann A. and Kolotylo C. (2009), The Professionalism and Environmental Factors in the Workplace Questionnaire (R): development and psychometric evaluation, J. Adv. Nurs., 65, 2216-2228.

Bluyssen P.M. (2000), EPIQR and IEQ: indoor environment quality in European apartment buildings, Energ. Buildings, 31, 103-110. 
Cho S.H., Lee T.K. and Kim J.T. (2011), Residents' satisfaction of indoor environmental quality in their old apartment homes, Indoor Built Environ., 20, 16-25.

Daisey J.M., Angell W.J. and Apte M.G. (2003), IAQ, ventilation and health symptoms in schools: an analysis of existing information, Indoor Air, 13, pp. 53-64.

Dascalaki E.G., Lagoudi A., Balaras C.A. and Gaglia A.G. (2008), Air quality in hospital operating rooms, Build. Environ., 43, 1945-1952.

Franchi M., Carrer P., Kotzias D., Rameckers E.M.A.L., Seppänen O., Van Bronswijk J.E.M.H., Viegi G., Gilder J.A. and Valovirta E. (2006), Working towards healthy air in dwellings in Europe, Allergy, 61, 864-868.

Glanz K. and Steffen A. (2008), Development and reliability testing for measures of psychosocial constructs associated with adolescent girls' calcium intake, J. Am. Diet. Assoc., 108, 857-861.

Harada K., Hasegawa A., Wei C.N., Minamoto K., Noguchi Y., Hara K., Matsushita O., Noda K. and Ueda A. (2010), A review of IAP and health problems from the viewpoint of environmental hygiene: focusing on the studies of indoor air environment in Japan compared to those of foreign countries, J. Health Sci., 56, 488-501.

Healy J.D. and Clinch J.P. (2002), Fuel poverty in Europe: A cross-country analysis using a new composite measurement, Environmental Studies Research Series, Working Papers, University College Dublin.

Hellenic Parliament (2010), Report of the special permanent committee for environmental protection, http://www.hellenicparliament.gr/UserFiles/510129c4-d278-40e7-8009-e77fc230adef/Ekthesi-ProstasiasPeriv.pdf, (last accessed November 20, 2012).

Helmis C.G., Assimakopoulos V.D., Flocas H.A., Stathopoulou O.I., Sgouros G. and Hatzaki M. (2009), IAQ assessment in the air traffic control tower of the Athens Airport, Greece, Environ. Monit. Assess., 148, 47-60.

Höppe P. (1988), Comfort Requirements in Indoor Climate, Energ. Buildings, 11, 249-257.

Höppe P. and Martinac I. (1998), Indoor climate and air quality, Int. J. Biometeorol., 42, 1-7.

Hwang R.L. and Chen C.P. (2010), Field study on behaviors and adaptation of elderly people and their thermal comfort requirements in residential environments, Indoor Air, 20, 235-245.

Jones A.P. (1999), IAQ and health, Atmos. Environ., 33, 4535-4564.

Karjalainen S. (2007), Gender differences in thermal comfort and use of thermostats in everyday thermal environments, Build. Environ., 42, 1594-1603.

Lahtinen M., Sundman-Digert C. and Reijula K. (2004), Psychosocial work environment and indoor air problems: a questionnaire as a means of problem diagnosis, Occup. Environ. Med., 61, 143-149.

Lee S.C., Li W.M. and Ao C.H. (2002), Investigation of IAQ at residential homes in Hong Kong - case study, Atmos. Environ., 36, 225-237.

Mendell M.J. and Mirer A.G. (2009), Indoor thermal factors and symptoms in office workers: findings from the US EPA BASE study, Indoor Air, 19, 291-302.

Santamouris M., Argiroudis K., Georgiou M., Pavlou K., Assimakopoulos M. and Sfakianaki K. (2007), IAQ in fifty residences in Athens, The 6th International Conference on IAQ, Ventilation \& Energy Conservation in Buildings, October 28 - 31 2007, Sendai, Japan.

Schieweck A. and Salthammer T. (2011), IAQ in passive-type museum showcases, J. Cult. Herit., 12, 205-213.

Sundell J. (2004), On the history of IAQ and health, Indoor Air, 14 (Suppl 7), 51-58.

Valavanidis A. and Vatista M. (2006), IAQ measurements in the chemistry department building of the university of Athens, Indoor Built Environ., 15, 595-605.

Wu F., Jacobs D., Mitchell C., Miller D. and Karol M.H. (2007), Improving Indoor Environmental Quality for Public Health: Impediments and Policy Recommendations, Environ. Health Persp., 115, 953-957. 